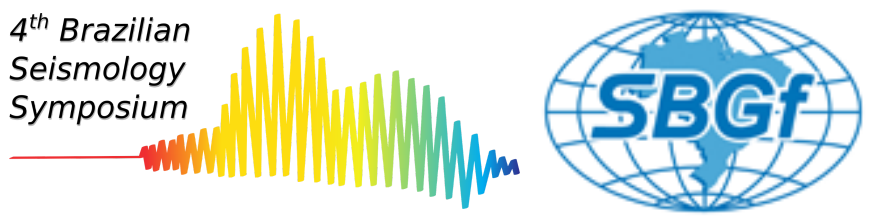

\title{
SEISMICITY IN THE WESTERN PORTION OF THE SÃO FRANCISCO CRATON: SEISMIC HAZARD IMPLICATIONS
}

Paulo Henrique Sousa de Oliveira ${ }^{1}$, George Sand França²,

1 (In Memoriam) Escola de Ciências e Tecnologia, Universidade Federal do Rio Grande do Norte,

${ }^{2}$ Observatório Sismológico, Instituto de Geociências, Universidade de Brasília

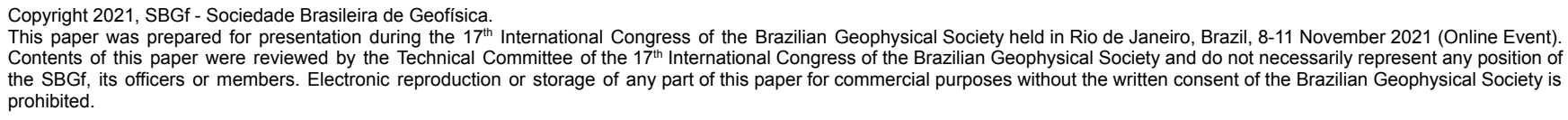

Copyright 2021, SBGf - Sociedade Brasileira de Geofísica.
This paper was prepared for presentation during the $17^{\text {th }}$ International Congress of the Brazilian Geophysical Society held in Rio de Janeiro, Brazil, $8-11$ November 2021 (Online Event). Contents of this paper were reviewed by the Technical Committee of the $17^{\text {th }}$ International Congress of the Brazilian Geophysical Society and do not necessarily represent any position of the SBGf, its officers or members. Electronic reproduction or storage of any part of this paper for commercial purposes without the written consent of the Brazilian Geophysical Society is prohibited.

This study aims at investigating seismicity by estimating recurrence times and seismicity rates in the western part of the São Francisco Craton, in central-northern Minas Gerais, and determining the Seismic Hazard Assessment. To this end, the Medium Return Period and the Exceedance Probability of a given magnitude earthquake to occur over different time windows were evaluated using a Poisson model. We determined the parameters "a" and "b-value" of the Gutenberg-Richter Law and the magnitude frequency distribution using data from earthquakes of magnitude between 0.50 and 3.7 Mw recorded in the study area between 1990 and 2019. The adjusted b-value $(0.54 \pm 0.04)$ and magnitude of completeness $(\mathrm{Mc}=0.90)$ allowed us to determine an Medium Return Periodo is 9.5 years for an Exceedance Probability is $10 \%$ in a one-year window and Exceedance Probability is $41 \%$ in a 5 -year window for the occurrence of a magnitude $4.0 \mathrm{mb}(3.72 \mathrm{Mw})$ earthquake. The Seismic Hazard Assessment was calculated based on a statistical analysis of existing data on the occurrence of earthquakes in the region. The results indicate that the probability of occurrence varies considerably over time, a characteristic that must be considered in any Seismic Hazard Assessment, which also shows, in a way, a rare characteristic of earthquakes in a Stable Continental Interior/Regions. 